\title{
Brain science, education, and learning: Making connections
}

\author{
P. T. M. Marope ${ }^{1}$
}

Published online: 29 April 2017

(C) UNESCO IBE 2017

From the press and the Internet's growing interest in the way the brain works, to commercial projects claiming that they are "brain based", fascination with the "learning brain" has recently exploded into the world's collective consciousness. The public excitement is matched by rigorous scientific efforts to bring biology and cognitive science into a closer relationship with education. As a field, the scholarship on brain research and education is as broad as it is deep and includes scholars working at the nexus of neuroscience, cognitive science, development, and education, but also sociology, anthropology, social psychology, medicine, and economics.

To be sure, this interest and demand for bringing brain science into closer register with education signifies more than a fad, a passing instance of "neuroscience cheerleading, to put it crudely" (McGinn 2014). There is a hope that brain research will foster "deeper knowledge of learning and teaching" and even begin to provide information that is useful for shaping educational practice and policy. Sometimes this hope can go "far beyond what is merited by the state of the emerging field of MBE [mind, brain, and education] and the level of knowledge about how brains and genetics function" (Fischer 2009, p. 4). Yet, an important motivation behind this new and exciting dialogue concerns the need to develop a twenty-first-century education system that is supported by concrete evidence of how we learn.

Why would building a scientific groundwork for learning, teaching, and assessment matter?

A number of factors place pressure on education systems to change swiftly and profoundly. They include rapid advances in communications and information technology; growing urbanization; concerns for environmental sustainability; shifts in geopolitics, demographic patterns, and labor markets; increasing unemployment, especially of young people; and the widening divide between rich and poor. Students need new and complex skills and competencies, not only to lead economically productive lives but also to

P. T. M. Marope

ibe.prospects@unesco.org

1 UNESCO International Bureau of Education (IBE), P.O. Box 199, 1211 Geneva, Switzerland 
transform themselves into "self-directed learners who can address their own wants and concerns and can advocate for their goals and aspirations" (UNESCO and UNICEF 2013, p. 24). Given unpredictable changes in technologies, work organization, international trade patterns, etc., no one can easily anticipate the kinds of skills workers will require later on. The breathtakingly rapid pace of change in the twenty-first century amplifies the pertinence of education and learning systems as foundations and key sources of lifelong learning and of human resilience. The emergence of the fourth industrial revolution is pressuring us to develop a wider range of multifaceted, multidisciplinary, complex, and integrated competencies, for which many education and learning systems are yet to be ready.

While policies about the role of education in development are commonplace, specific and concrete instruments for enacting these policies remain both scant and ineffective. In today's world, the perceived heightened role of education in human and societal development coexists with heightened frustration about the irrelevance of educational practices to modern challenges and opportunities. Some of the evidence for this frustration is the alienation of young graduates from their cultures, their functional illiteracy, their lack of digital skills required by their labor markets, etc.

Building a scientific groundwork offers hope, by providing an expanded, updated, and potentially useful toolkit for improving education and learning. For a long time, progress in developing new learning methods has lagged behind human accomplishment in many other areas, and changes in our approach to learning have been relatively modest. Scientific technologies and concepts, particularly from neuroscience and related fields, are aiming to change that.

Brain science is now providing new discoveries about the basic mechanisms of learning that can begin to inform, in an authentic manner, everyday practices. This is a two-way venture in which scientists can explore their concepts in "real world" environments, and education can gain insight into learning processes and practices. Techniques such as neuroimaging allow us to study brain function while active learners acquire skills. Through understanding the underlying processes of learning, educators and scientists are starting to collaborate on developing neurocognitive and psychological interventions (for typical and atypical learners) for improving literacy, numeracy, reasoning, and many other skills. Thus, understanding the "learning brain" can provide an additional tool for educators and parents to facilitate students' learning and development. Moreover, cognitive science can give us potent means to understand, prevent, and heal societal prejudices and stereotypes that seep into the minds of very young children (Meltzoff 2013; Skinner et al. 2017).

Neuroscience is revolutionizing our understanding of learning and revealing a fresh perspective that combines mind and brain. Key concepts such as ability, disability, learning preferences, creativity, flexibility, self-regulation, to name a few, can be described in the new light of differences in how individual learners' brains work and adapt to their physical and social environments. Many factors, within and beyond the classroom, "sculpt" the unique brain of an individual learner.

Cutting-edge research is also introducing new dimensions that have not traditionally or explicitly been linked to classroom learning, such as emotion, and underlying environmental, evolutionary, and biological variables-all factors that are both potential constraints and potential springboards for acquiring human learning and knowledge.

Including in teacher training and development a basic grounding about how the brain learns promises to expand teachers' education and empower them to approach their own practice more scientifically. Teachers carry a unique professional responsibility, on a dayto-day basis, for influencing and helping young children to learn new things, which at a neurobiological level literally means changing the structure, functioning, and connectivity 
of young brains. Thus, teachers have a justifiable interest in understanding the mechanisms involved. They constantly adapt their teaching to the learner(s) and the context, applying their own theories about their students' mental processes and how to influence these processes to scaffold learning. An increased exposure to the new scientific understanding of learning should be regarded as fundamental to every teacher's continuing education.

A scientific understanding of learning is also particularly relevant for ensuring educational reform in a culturally diverse world, respect for which is emphasized in Sustainable Development Goal (SDG) 4: By 2030, ensure that all learners acquire the knowledge and skills needed to promote sustainable development, including, among others, through education for sustainable development and sustainable lifestyles, human rights, gender equality, promotion of a culture of peace and non-violence, global citizenship and appreciation of cultural diversity and of culture's contribution to sustainable development. Teachers' response to top-down reform necessarily involves their own process of cultural adaptation, integrating their own reflections, attitudes, and behaviors with the recommended changes. In other words, teachers will always adapt what they are given and make it their own. This undermines any sense that a "one-size fits all" approach to educational reform can ever be entirely successful. Success will rely, in large part, on teachers' own interpretation of how learning works and how ideas might, therefore, best be adapted for their students (Cunnington, D’Angiulli, Howard-Jones, Prado, and Reigosa-Crespo 2017).

The International Bureau of Education (IBE) is deeply involved with these issues. The IBE aims to improve access to evidence-based knowledge needed to guide curriculum design and development, and teaching, learning, and assessment within the demands of the global education 2030 agenda. For the past two years, the IBE has focused its knowledge brokerage on two main themes, which are interconnected and directly contribute to the achievement of SDG4: learning (specifically, the neuroscience of learning) and the development-relevance of curriculum (specifically, future competencies).

For instance, in partnership with the International Brain Research Organization (IBRO), the IBE has begun to translate research on the neuroscience of learning; it initiated the IBE-IBRO Science of Learning Fellowship to support and translate key neuroscience research on learning and the brain for educators, policymakers, and practitioners. The first cohort of 5 senior fellows joined the IBE in October 2016, producing 30 briefs that address prevalent neuromyths and outline the basics of such issues as neuroplasticity and numerical processing and the potential implications of these issues for learning, teaching, and assessment. Over the coming year, 3 more neuroscientists will be working with the IBE staff to explore how current problems and needs in education can drive new directions for neuroscience research, and how neuroscience can feed into educational thinking, policy, and practice.

This is, therefore, a particularly opportune time for the IBE to publish this special issue of Prospects, which brings together leading scholars from neuroscience and psychology with a strong interest in education and social sciences. In these pages, they engage critically and articulate innovative analytical frameworks for examining the links between their fields and education and learning.

Scholarly distinction is a prerequisite in such work, but the ideal editors and authors also need to be able to make this topic relevant to a readership beyond their specific research field. This was a challenge that Andrew Meltzoff and Roberto Lent, the guest editors of this special issue, set themselves from the beginning. Professor at the University of Washington, where he holds the Tamaki Chair, and co-director of the Institute for Learning \& Brain Sciences, Andrew Meltzoff is a psychologist and an internationally recognized expert on infant and child development. Roberto Lent is professor and director of the 
Institute of Biomedical Sciences, Federal University of Rio de Janeiro, and coordinator of the Brazilian Network of Science for Education (Rede CpE).

When we first met both of them in 2015, in Rio de Janeiro, at the International Symposium on Science for Education (an initiative of the Brazilian Network of Science for Education and a satellite event of the 9th World Congress on Neuroscience, organized by IBRO), we couldn't have anticipated the excellent collection of articles based on the conference presentations. Equally important, a very strong learning community developed from the symposium between the IBE/IBRO, the guest editors, and the authors. This special issue builds on and further strengthens these partnerships, which aim at integrating scientific research with policy and practice to improve education and learning for all.

\section{References}

Cunnington, R., D’Angiulli, A., Howard-Jones, P., Prado, J., \& Reigosa-Crespo, V. (2017). 21st century education and the learning brain. In Focus. Annual magazine. Geneva: UNESCO IBE.

Fischer, K. W. (2009). Mind, brain, and education: Building a scientific groundwork for learning and teaching. Mind, Brain, and Education, 3(1), 3-16.

McGinn, C. (2014). Storm over the brain. New York Review of Books, April 24 issue.

Meltzoff, A. N. (2013). Origins of social cognition: Bidirectional self-other mapping and the "Like-Me" hypothesis. In M. R. Banaji \& S. Gelman (Eds.), Navigating the social world: What infants, children, and other species can teach us (pp. 139-144). New York, NY: Oxford University Press.

Skinner, A. L., Meltzoff, A. N., \& Olson, K. R. (2017). "Catching" social bias: Exposure to biased nonverbal signals creates social biases in preschool children. Psychological Science, 28(2), 216-224. doi:10.1177/0956797616678930.

UNESCO \& UNICEF (2013). Making education a priority in the post-2015 development agenda. Report of the global thematic consultation on education in the post-2015 development agenda. Paris \& New York: UNESCO and UNICEF. 